\title{
Estudo de redução de custo de fabricação e montagem em um motor a diesel com o auxilio do DFMA
}

\author{
Carla Estorilio, Dr. \\ Depto. de Mecânica - UTFPR \\ amodio@cefetpr.br
}

\author{
Marcelo César Simião; Cleiton Luis Schonoski; Murilo César de Lara \\ Engenheiros Mecânicos - UTFPR \\ mcsimiao@hotmail.com; cleitoncanada@hotmail.com; murilo_lara@yahoo.com.br
}

\begin{abstract}
Esse artigo apresenta uma revisão de projeto de um motor a diesel fabricado em Curitiba, visando reduzir custos de fabricação e montagem com o objetivo de torná-lo economicamente viável. O trabalho apresenta uma breve revisão sobre desenvolvimento de produto e recursos de apoio ao projeto de produto industrial, detalhando o método DFMA (Design for Manufacturing and Assembly - Projeto para manufatura e montagem). O artigo apresenta como o subsistema mais crítico do motor foi identificado, considerando o fator custo, e mostra a aplicação das diretrizes do DFMA para este subsistema. Os resultados da revisão de projeto mostram um impacto na redução de custo do subsistema estudado na ordem de $1,8 \%$ e do motor completo em $0,7 \%$.
\end{abstract}

Palavras-chave: revisão de projeto, redução de custo, DFMA

This work presents a study of manufacture and assembly costs reduction of a diesel engine model manufactured in an industry located in Curitiba, which aims at making this engine economically feasible. The study presents a brief review about product development and technological resources to support the product design, emphasizing the DFMA (Design for Manufacturing and Assembly) method. This paper presents a detailed description of how delimited the most critical subsystem of the engine was, considering the cost and the application of DFMA guidelines for this delimited subsystem. The results show an impact in the cost reduction of the subsystem chosen of $1.8 \%$ and in the entire engine of $0.7 \%$.

Keywords: design review, cost reduction, DFMA

\section{Introdução}

A competição e a globalização levaram as empresas a introduzirem com mais rapidez os seus produtos no mercado, com menor custo e melhor qualidade, exigindo uma reestruturação dos seus processos de desenvolvimento de produtos (ANDREASEN et al., 1988; BOOTHROYD; DEWHURST, 1990; BLACKBURN, 1991; WHEELWRIGHT; CLARK, 1992; BOOTHROYD, 1994; BARNETTECLARK, 1998).

Em função desses fatores, muitas empresas têm buscado os benefícios provenientes das tecnologias de apoio ao desenvolvimento de produto e, principalmente, daquelas que contribuem com a etapa de projeto (ESTORILIO, 2003).
Segundo a classificação do NUMA (Núcleo de Manufatura Avançada da USP de São Carlos), esses recursos tecnológicos podem ser enquadrados em três categorias distintas. São elas: as ferramentas (relacionadas aos softwares), as metodologias (que envolvem aspectos conceituais mais abrangentes) e os métodos. Estes envolvem conhecimentos restritos a determinado tema e normalmente são estruturados em passos ou relacionados com algo específico, visando atingir um objetivo. Um método pode estar relacionado a uma metodologia, conceito ou filosofia, podendo ser até classificado como tal (ROZENFELD etal., 2006). 
Entre os métodos, pode-se citar: o QFD (Quality Function Deployment) (AKAO, 1990) - usado para desdobrar as necessidades dos clientes nas primeiras características técnicas do produto; o FMEA (Failure Mode and Effect Analysis) (PALADY, 2002) - usado para antecipar e prevenir as possíveis falhas do produto em uso ainda na etapa de projeto e os DFX (Design for X)(YANG;EL-HAIK, 2003) - que são métodos que auxiliam o projetista a repensar o projeto visando simplificar e facilitar a fabricação, a montagem, a manutenção e outros aspectos relacionados ao produto.

Segundo Pereira e Manke (2001), esses métodos contribuem para fundamentar a base de conhecimento necessária no projeto de um produto e vêm sendo associados a conceitos como Engenharia Simultânea, Seis Sigma e outros conceitos.

De acordo com Back e Ogliari (2000), as decisões tomadas na etapa de projeto do produto não só tem um efeito significativo nos custos de produção como também na própria manufaturabilidade dos produtos. Portanto, decisões não acertadas durante o projeto podem comprometer, em maior ou menor grau, não somente o custo e o tempo de desenvolvimento, mas também, a integridade do produto nas demais fases do seu ciclo de vida.

Segundo Savoie et al. (1990), o custo de manufatura é comprometido durante o projeto porque suas definições tendem a afetar a fabricação do ferramental utilizado na produção, responsável pela maior parte do desembolso efetuado.

Entre os métodos de apoio ao projeto do produto, que auxilia a considerar a manufatura e a montagem durante a etapa de projeto, está o Design for Manufacturing and Assembly (DFMA). Este método pertence à categoria dos DFX (Design for X) e é utilizado como apoio para melhorar o conceito de um produto ou um projeto já existente, resultando em um projeto mais bem elaborado. Afinal, o objetivo do DFMA é contribuir para a geração de um projeto dentro da capacidade de manufatura da empresa, visando, também, facilitar a montagem do produto final.

O termo Design for Manufacturing (DFM) significa projeto para fácil fabricação de lotes de componentes que irão formar o produto após a montagem e o termo Design for Assembly (DFA) significa projeto para fácil montagem. O processo de manufatura se refere à fabricação de um componente que faz parte de um conjunto e o processo de montagem se refere à adição de partes para formar um produto completo (BOOTHROYD, 1994).

Com o objetivo de testar o método DFMA em um caso prático de projeto de produto, este artigo apresenta um estudo de redução de custo de manufatura e montagem em um projeto de motor pertencente a uma empresa loca- lizada em Curitiba para torná-lo economicamente viável.

A empresa desenvolvedora do motor em questão é uma multinacional de grande porte, a qual desativou uma linha de motores devido ao alto custo de operação, baixa permutabilidade e o não atendimento dos requisitos ambientais e evoluções do mercado de motores a diesel.

Para se adequar às necessidades do mercado, uma nova linha de motores foi projetada, porém, na fase de implementação, esta série não atendeu ao requisito relativo ao custo, evidenciando a necessidade de uma revisão e melhoria dos projetos para evitar o cancelamento de um considerável volume de produção.

Para realizar esse trabalho de melhoria de projeto, os métodos DFM (Projeto para Manufatura) e DFA(Projeto para Montagem) foram adotados como apoio, aplicando suas diretrizes no motor de mais alto custo da série.

Com os resultados das análises, alterações de projeto são sugeridas e incorporadas ao projeto original, sendo emitida uma nova documentação do produto, a qual é comparada com a documentação do projeto original com o objetivo de quantificar os respectivos ganhos em custo.

\section{Metodologia de pesquisa}

Considerando o objetivo da pesquisa que é o de reduzir o custo de um motor a diesel através da melhoria do seu projeto, a seguinte metodologia é aplicada: primeiramente é realizada uma revisão dos projetos da linha de motores a diesel da empresa estudada, considerada crítica pelo seu alto custo, visando identificar o motor de mais alto custo, o qual é denominado neste trabalho de "motor X".

O método utilizado como apoio para a revisão do projeto do motor X é o DFMA, em função de suas característica que permitem uma revisão relacionada com os aspectos que impactam nos custos de fabricação e montagem.

Este método quase sempre produz uma considerável redução na lista de peças, resultando em produtos mais confiáveis, mais simples e mais baratos para montar e produzir. Esta redução no número de partes tem um efeito significativo sobre a redução dos custos, identificando os vários itens desnecessários e outros desperdícios (HUANG 1996).

O método fornece uma medição quantitativa da eficiência do projeto, permitindo comparar o tempo total de montagem do produto com o tempo de montagem do produto ideal após as melhorias. O mesmo procedimento poderia ser utilizado para comparar vários projetos diferentes em termos de suas eficiências relativas (BOOTHRYD ; DEWHURST, 1990). 
Para aplicar o DFMA no motor $\mathrm{X}$, as seguintes diretrizes sugeridas por Joneja (2005) são seguidas:

1. Obter detalhes do projeto, desenhos de engenharia, modelos tridimensionais (3D), protótipo físico ou o próprio produto.;

2. Desmontar o conjunto observando a seqüência e como cada parte é desmontada. Considerar as sub-montagens como partes separadas, identificando cada uma delas;

3. Começar a remontagem do produto desde a identificação maior até a menor, anotando os tempos de montagem;

4. Calcular a eficiência do projeto através da seguinte fórmula: $\mathrm{EP}=3$ x NP / TM, sendo (EP: eficiência do projeto, NP: número de partes e TM: tempo de montagem).

Após a análise da montagem, a manufatura de cada componente é analisada, considerando as diretrizes do DFMA descritas no decorrer deste trabalho.

\section{Motor a diesel}

Motor a diesel ou motor por ignição por compressão é um motor que obtém a ignição sem uma intervenção exterior. A ignição do combustível é obtida com o aporte de energia através da fase de compressão. $\mathrm{O}$ aumento na temperatura e pressão durante a compressão é suficiente para gerar a ignição espontânea do combustível (RAYNAL, 2005).

Segundo o autor, para que exista um funcionamento satisfatório dos motores a diesel é necessário um controle do combustível e do ar injetados na câmara de combustão, o qual ocorre através do sistema de injeção.

Os motores a diesel podem ser divididos em duas categorias de acordo com o desenho da câmara de combustão: motores a diesel de injeção direta e motores a diesel de injeção indireta. Os motores de injeção direta, que é o caso do motor X estudado, possuem apenas uma câmara de combustão onde o combustível é injetado diretamente.

Os principais componentes de um motor a diesel são:

- Bloco do cilindro: estrutura rígida que mantém os cilindros em um alinhamento apropriado;

- Bomba injetora: faz a pressurização do combustível nas linhas de alta pressão no momento da injeção;

- Cilindros: tubos nos quais os pistões deslizam para cima e para baixo em seu interior;

- Cabeçote: delimita, juntamente com o pistão, o volume da câmara de combustão;

- Carter de óleo: estrutura rígida situada na parte inferior do motor que permite alimentar o sistema de lubrificação dos elementos móveis do motor;

- Pistão: assegura a estanqueidade entre a câmara de combustão e o bloco. Quanto o pistão é submetido à pressão dos gases, ele transmite a força da explosão para a biela através do seu eixo;

- Biela: transmite a força exercida pelo pistão quando a mistura ar-combustível queima;

- Virabrequim: transforma o movimento alternativo de vaivém dos êmbolos em movimento rotativo e transmite a potência do motor para a caixa de transmissão, a qual retransmite para as rodas;

- Volante: mantém o movimento de rotação da árvore de manivelas uniforme, fazendo o virabrequim girar a uma velocidade constante;

- Válvulas: cada cilindro tem uma válvula de admissão por onde entra a mistura a ser queimada e uma válvula de expulsão, para deixar que os gases queimados escapem;

- Eixo de comando: responsável em abrir e fechar as válvulas (STONE, 1995; PERKINS ENGINES CORP., 2004; VELASQUEZ, 2005; LOCTITE, 2006).

O próximo item apresenta as características do motor $\mathrm{X} \mathrm{e}$ o desenvolvimento da análise realizada com o apoio do método DFMA.

\section{Aplicação do DFMA no motor $X$}

Analisando o projeto do motor $\mathrm{X}$ identificou-se que o tempo de produção é de aproximadamente 5 horas e 35 minutos e a capacidade de produção é de um motor a cada 7 minutos.

Foram estudados os processos de fabricação, montagem, teste e embalagem do motor $\mathrm{X}$, chegando-se à seguinte seqüência:

1. Recebimento dos componentes;

2. Inspeção de recebimento dos componentes;

3. Disponibilização dos componentes na linha de montagem;

4. Montagem do motor na linha principal;

5. Teste de dinamômetro do motor durante 31 minutos para verificação do torque, potência, ruídos, falta de balanceamento, ajuste de válvulas e vazamentos;

6. Montagem de itens para transporte do motor tais como tampas e tampões roscados na linha de montagem final;

7. Aplicação de fluido anticorrosivo no motor;

8. Disponibilização do motor para transporte até o cliente. 
O detalhamento do processo de montagem do motor $\mathrm{X}$ não consta neste artigo em função da quantidade excessiva de informações.

\subsection{Delimitação do subsistema mais crítico}

Analisando os custos de fabricação do motor X, constata-se a aplicabilidade do DFMA considerando que os componentes representam 66,23\% do custo total. Outros custos estão relacionados com o frete, impostos e outros fatores.

Para a identificação dos componentes a serem submetidos às análises, relacionaram-se os componentes partindo do de maior custo ao de menor. Delimitou-se como "componentes relevantes" os primeiros da lista que, juntos, somavam 98,5\% do custo total.

Em seguida, os componentes do motor $\mathrm{X}$ foram associados aos seguintes subsistemas:

- Estrutural e vedações (cabeçote, bloco de cilindros, juntas, etc.);

- Elementos rotativos (virabrequim, engrenagens, polia amortecedora, volante, bronzinas, bielas, selos de virabrequim, bomba de água);

- Injeção (bomba injetora, bicos injetores, tubos de alta pressão, etc.);

- Ar, lubrificante e refrigeração (válvulas de recirculação de gases, trocadores de calor, coletores, bomba de água, etc.);

- Válvulas (eixo comando, válvulas, assentos, molas, balancins, varetas) e Cilindro (camisas, pistões, pinos, anéis de pistão, bicos resfriadores, etc.).

Para constatar a necessidade da existência dos componentes acima relacionados no projeto estudado, três perguntas foram feitas para cada um deles, recomendadas por Boothroyd (1994):

a) Existe necessidade de movimento relativo entre as partes?

b) Existe necessidade de especificação de diferentes materiais por razões físicas e/ou químicas?

c) O componente deve ser desmontável para facilitar a manutenção?

Os que apresentaram respostas positivas mostraram menos flexibilidade para alterações, segundo as diretrizes do DFMA.

Para organizar estes e outros resultados, uma tabela foi formatada contendo os seguintes itens: Quantidade do componente em questão; Descrição do componente; Subsistema ao qual pertence; Percentual do custo do componente em relação ao custo total dos componentes considerados relevantes no motor e as três perguntas (a, b e c) previamente citadas.

Analisando esta tabela, determinou-se que o subsistema a ser estudado seria o Estrutural e Vedações, considerando a sua representação de $37,915 \%$ no custo total dos componentes relevantes do motor e pelo fato de ter obtido $100 \%$ de respostas negativas à pergunta 1, 73\% de respostas negativas à pergunta 2 e 53\% de respostas negativas à pergunta 3, demonstrando, assim, certa flexibilidade para alterações de projeto.

Dos componentes pertencentes a esse subsistema, quatro foram escolhidos para o estudo, em função do percentual de custo dentro dos 37,915\%: o Bloco de cilindros (19,99\%), o Cabeçote (8,35\%), o Carter de óleo (3,67\%) e a Caixa de engrenagem (1,55\%). Os outros componentes mostraram percentuais abaixo de 1,5\% dos 37,915\%, sendo, portanto, desconsiderados neste estudo.

\subsection{Aplicação do DFMA para o bloco de cilindros}

O bloco de cilindros não possui camisas, possui refrigeração aberta e é estruturado para encaixe direto na caixa de engrenagens do trator (Ver Figura 1).

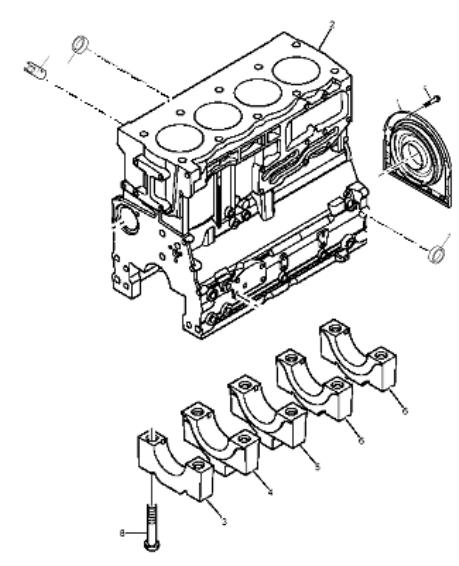

Figura 1 - Bloco de cilindros em perspectiva

Primeiramente, calculou-se a eficiência de projeto, considerando a formula: (EP = 3 x NP / TM), sendo (EP: eficiên- 
cia do projeto, NP: número de partes e TM: tempo de montagem), detalhada na Tabela 1 . O objetivo desse cálculo é comparar, após as alterações de projeto resultantes da aplicação do DFMA, o quanto se conseguiu um acréscimo na eficiência do projeto.

Para revisar o projeto, aplicando o DFMA, as seguintes diretrizes foram seguidas:

•Projetar para um número mínimo de partes;

-Desenvolver projetos modulares;

- Projetar componentes multifuncionais;

- Projetar componentes de fácil fabricação;

- Evitar ou reduzir componentes de fixação (parafusos, rebites, pinos);

•Eliminar ajustes e tolerâncias desnecessários;

-Enfatizar a padronização de componentes;

- Reduzir o número de partes de um produto;

- Facilitar a manipulação e a montagem das partes restantes;

- Simplificar a estrutura do produto para reduzir os custos de montagem e outros fatores dessa natureza.
Após analisar o bloco de cilindros, segundo essas diretrizes, identificaram-se várias possibilidades de melhorias, entre elas, a eliminação dos furos das capas do mancal, mostrados na Figura 2.

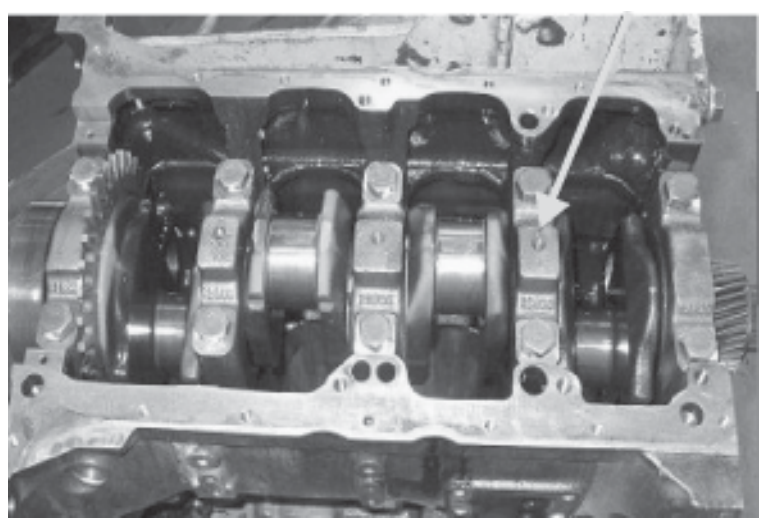

Figura 2 - Furos das capas do mancal no bloco de cilindros

Após o acompanhamento do processo de montagem e junto ao fornecedor da peça, observou-se que esses furos usinados e não-passantes são desnecessários para a continuidade da montagem, pois não têm contato direto

Tabela 1 - Cálculo da eficiência de projeto do bloco de cilindros antes do estudo

\begin{tabular}{|c|c|c|c|c|c|}
\hline C1 & $\mathrm{C} 2$ & C3 & C4 & C5 & C6 \\
\hline 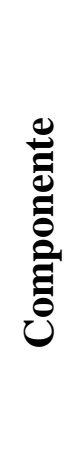 & & 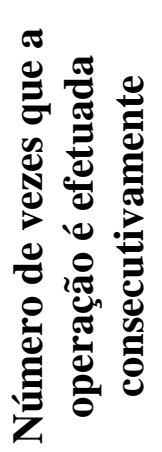 & 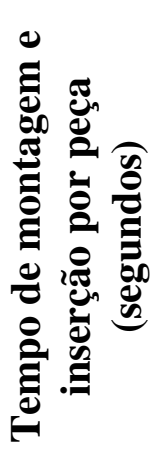 & 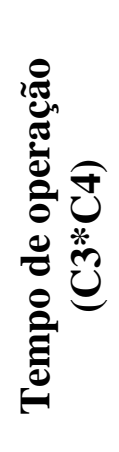 & 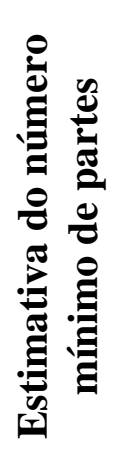 \\
\hline 1 & Tampão da alimentação de óleo & 1 & 20 & 20 & 1 \\
\hline 2 & Tampão do dreno de óleo & 1 & 20 & 20 & 1 \\
\hline 3 & Bloco de cilindros & 1 & 30 & 30 & 1 \\
\hline 4 & Parafusos do selo traseiro de óleo & 10 & 8 & 77 & 10 \\
\hline 5 & Selo traseiro de óleo & 1 & 14 & 14 & 1 \\
\hline 6 & Tampão do sensor de velocidade & 1 & 20 & 20 & 0 \\
\hline 7 & Plaqueta do número de série & 1 & 60 & 60 & 0 \\
\hline 8 & Capas de mancal & 5 & 18 & 90 & 5 \\
\hline 9 & Parafusos das capas de mancal & 10 & 5 & 50 & 10 \\
\hline & & & & TM & NP \\
\hline & & & & 381 & 29 \\
\hline \multicolumn{4}{|c|}{ Eficiência do projeto } & & 0,23 \\
\hline
\end{tabular}


Detectou-se que o motivo da existência desses furos era devido ao aproveitamento do projeto de um bloco de cilindros de outra série de motores que utilizava esses furos para fixar o pescador de óleo. Na série do motor X, o pescador de óleo é fixado no conjunto balanceiro, o qual é fixado no bloco, tornando os três furos desnecessários.

Em função desta alteração, a redução de custo ocorre como conseqüência da economia de tempo de máquina, desgaste de ferramenta e tempo de inspeção dos três furos. Quantificando essa redução, conclui-se que impacta em $0,05 \%$ no custo do bloco de cilindros e $0,03 \%$ no custo do subsistema "estrutural e vedações".

Outro resultado da análise foi eliminar a pintura do bloco. O bloco de cilindros tem como etapa do seu processo de fabricação a pintura eletrostática em preto após a fundição, como mostrada na Figura 3. Esta etapa tem como objetivo proteger o bloco de cilindros contra a corrosão durante o trajeto do fornecedor até a fábrica destino.

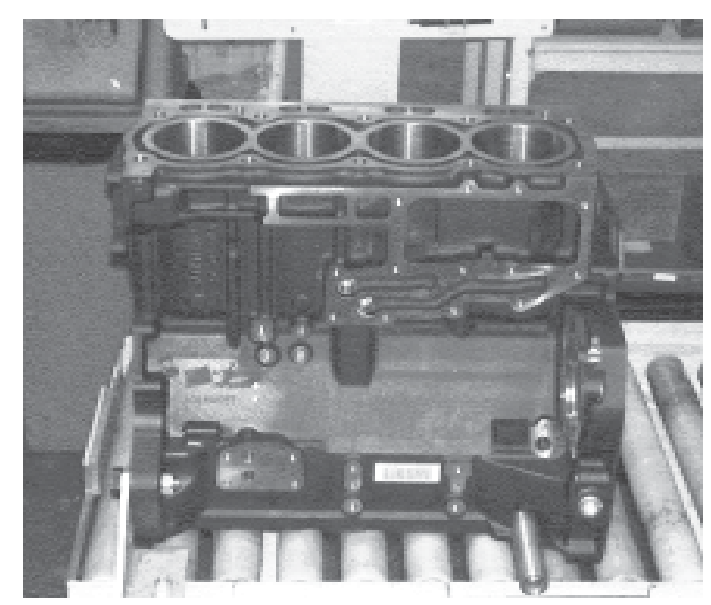

Figura 3 - Bloco de cilindros pintado

Antes do embarque do lote produzido pelo fornecedor, os blocos de cilindros recebem uma aplicação de óleo anticorrosivo e são embalados em plásticos com inibidores de corrosão. Essa proteção era necessária quando o fornecedor estava na Europa, o que demandava um trânsito de um mês. Com a nacionalização do bloco, o tempo de transporte foi reduzido para dois dias, não havendo a necessidade de tanta proteção.

Além disso, constatou-se que durante a montagem do motor no trator, o conjunto do motor e chassi era pintado de preto por inteiro, recobrindo qualquer pintura anterior do motor. Sendo assim, a pintura do bloco de cilindros torna-se redundante.

Com essa modificação ocorre uma redução de custo de $0,26 \%$ no custo do bloco de cilindros e $0,13 \%$ no custo do subsistema "estrutural e vedações".
Outra proposta de modificação foi a eliminação do furo e faceamento do assento do sensor de velocidade. O furo passante de diâmetro nominal 17,1mm, a rosca M6 e o faceamento mostrados na Figura 4 são necessários apenas nos modelos com injeção através de bomba de combustível eletrônica. Esta série possui um sistema mecânico de injeção, tornando estas características desnecessárias.

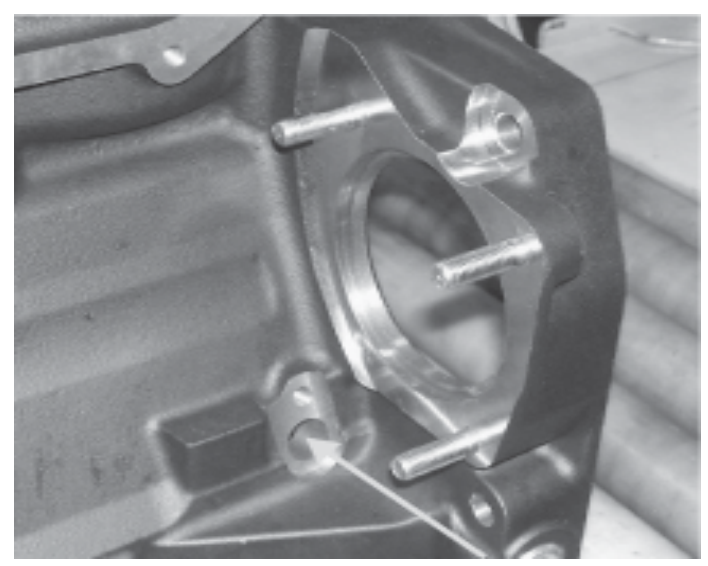

Figura 4 - Furo e faceamento do sensor de velocidade

Essa modificação resulta em uma redução de custo de $0,18 \%$ no custo do bloco de cilindros e $0,10 \%$ no custo do subsistema "estrutural e vedações".

Seguindo com a análise, outra proposta de modificação foi a eliminação da placa de identificação do número de série do motor, usada para registrar o histórico do produto.

Essa operação consiste em gravar uma placa de alumínio e utilizar dois rebites para fixá-la no bloco (Ver Figura 5). Se a gravação for realizada diretamente no bloco de cilindros, a placa e os rebites tornam-se desnecessários. Neste caso, a modificação resulta em uma redução de custo de $0,29 \%$ no custo do bloco de cilindros e $0,15 \%$ no custo do subsistema "estrutural e vedações".

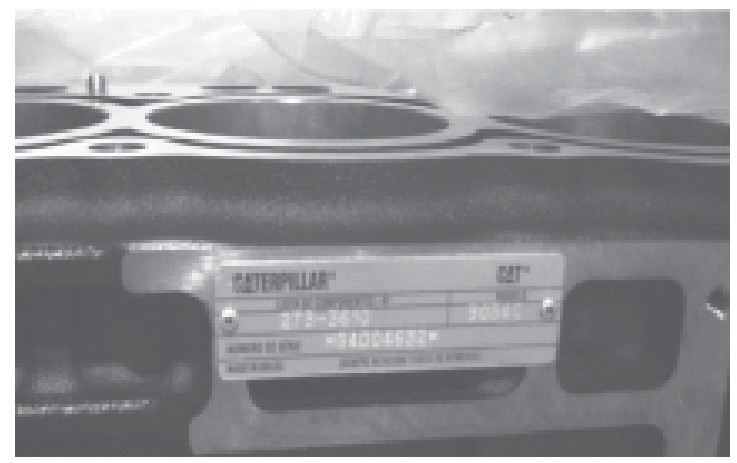

Figura 5 - Placa de identificação do motor

Considerando as modificações para o "bloco de cilindros", os cálculos da eficiência do projeto foram refeitos, resultando em uma melhoria na ordem de 0,23 para 0,29. O 
custo do subsistema foi reduzido em 0,41\%, como pode ser visto na Tabela 2. Essa tabela apresenta os mesmos componentes da Tabela 1, porém, explicita a exclusão dos itens 6 e 7, conforme as modificações sugeridas.

\subsection{Aplicação do DFMA para outros componentes}

Além das alterações sugeridas no bloco de cilindros, outras modificações também foram sugeridas e contabilizadas para os outros componentes previamente citados; o cabeçote, o cárter de óleo e a caixa de engrenagem. Os resultados dessas alterações e seus impactos nos custos podem ser vistos, sucintamente, nas Tabelas 3, 4 e 5.

Com a implementação das modificações propostas para o Cabeçote de cilindro, não se constata melhoria na eficiência do projeto para montagem, mantendo o valor de 0,49 . Identifica-se, porém, uma redução de custo do subsistema "estrutural e vedações" em 0,10\%, em função dos ganhos na manufatura.

Com a implementação das modificações propostas para o
Carter de óleo, a eficiência do projeto melhora de 0,19 para 0,20 e o custo do subsistema "estrutural e vedações" é reduzido em $0,90 \%$.

Com a implementação da modificação proposta para a Caixa de engrenagem, a eficiência do projeto melhora de 0,53 para 0,58 e o custo do subsistema "estrutural e vedações" é reduzido em 0,53\%.

\subsection{Síntese das soluções}

A síntese das características analisadas, as propostas de melhorias e respectivas reduções de custos estão demonstradas na Tabela 6.

Em relação às reduções totais do custo do subsistema estrutural e vedações e do custo total do motor X identificaram-se as seguintes:

- Redução total no custo do subsistema: 1,94\%

- Redução total no custo do motor: 0,71\%

Tabela 2 - Eficiência do conjunto do bloco de cilindros após as alterações com a aplicação do DFMA

\begin{tabular}{|c|c|c|c|c|c|}
\hline $\mathbf{C 1}$ & $\mathrm{C} 2$ & C3 & $\mathrm{C4}$ & $\mathbf{C 5}$ & C6 \\
\hline 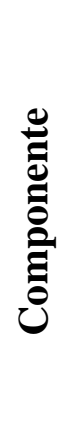 & 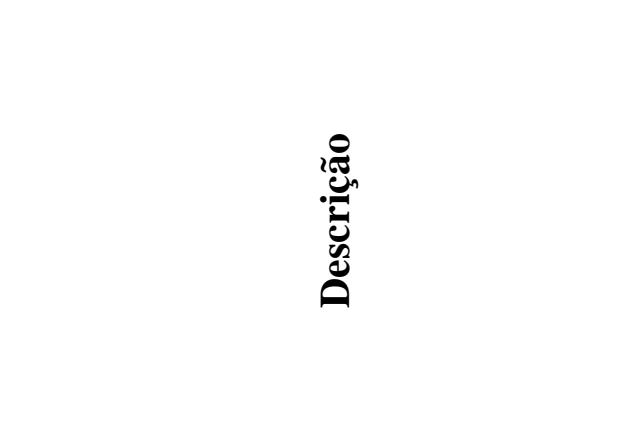 & 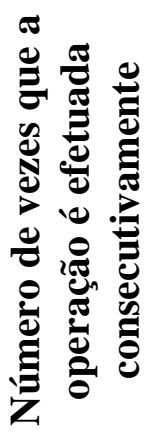 & 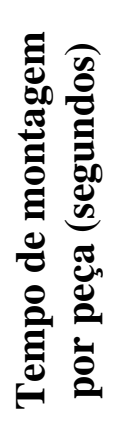 & 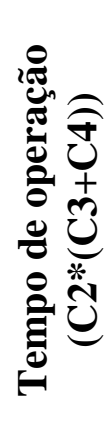 & 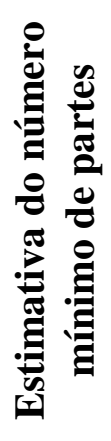 \\
\hline 1 & Tampão da alimentação de óleo & 1 & 20 & 20 & 1 \\
\hline 2 & Tampão do dreno de óleo & 1 & 20 & 20 & 1 \\
\hline 3 & Bloco de cilindros & 1 & 30 & 30 & 1 \\
\hline 4 & Parafusos do selo traseiro de óleo & 10 & 8 & 77 & 10 \\
\hline 5 & Selo traseiro de óleo & 1 & 14 & 14 & 1 \\
\hline 6 & Tampão do sensor de velocidade & & & & \\
\hline 7 & Plaqueta do número de série & & & & \\
\hline 8 & Capas de mancal & 5 & 18 & 90 & 5 \\
\hline 9 & Parafusos das capas de mancal & 10 & 5 & 50 & 10 \\
\hline & & & & TM & NP \\
\hline & & & & 301 & 29 \\
\hline \multicolumn{4}{|c|}{ Eficiência do projeto } & & 0,29 \\
\hline
\end{tabular}


Tabela 3 - Modificações sugeridas para o cabeçote de cilindro

\begin{tabular}{|c|c|c|}
\hline \multicolumn{3}{|c|}{ Cabeçote de cilindro (impacta em 8,4\% dos 37,915\%) } \\
\hline $\begin{array}{c}\text { Modificações } \\
\text { sugeridas }\end{array}$ & Justificativa & Impactos no custo \\
\hline $\begin{array}{l}\text { Eliminação do } \\
\text { faceamento ao redor do } \\
\text { assento dos bicos } \\
\text { injetores. }\end{array}$ & $\begin{array}{l}\text { A montagem do bico injetor e } \\
\text { travamento são feitas através do } \\
\text { mecanismo de pinça que empurra o bico } \\
\text { injetor para dentro da câmara de } \\
\text { combustão, fazendo a vedação na bucha } \\
\text { térmica. Nem o bico injetor nem a pinça } \\
\text { tocam a área faceada, tornando-a } \\
\text { desnecessária. }\end{array}$ & $\begin{array}{l}\text { Redução de custo de } 0,18 \% \\
\text { do custo do cabeçote de } \\
\text { cilindro e } 0,04 \% \text { do custo do } \\
\text { subsistema } \\
\text { “estrutural e vedações”. }\end{array}$ \\
\hline $\begin{array}{l}\text { Eliminação da pintura } \\
\text { eletrostática do cabeçote. }\end{array}$ & $\begin{array}{l}\text { Com a redução do tempo de transporte } \\
\text { de um mês para dois dias, esse nível de } \\
\text { proteção tornou-se desnecessária. }\end{array}$ & $\begin{array}{l}\text { Redução de custo de } 0,26 \% \\
\text { no custo do cabeçote e } 0,06 \% \\
\text { no custo do subsistema } \\
\text { “estrutural e vedações”. }\end{array}$ \\
\hline
\end{tabular}

Tabela 4 - Modificações sugeridas para o cárter de óleo

\begin{tabular}{|c|c|c|}
\hline \multicolumn{3}{|c|}{ Cárter de óleo (impacta em 3,67\% dos 37,915\%) } \\
\hline $\begin{array}{c}\text { Modificações } \\
\text { sugeridas }\end{array}$ & Justificativa & Impactos no custo \\
\hline $\begin{array}{l}\text { Eliminação da junta do } \\
\text { Carter de óleo. }\end{array}$ & $\begin{array}{l}\text { Esta junta é composta de uma liga de } \\
\text { alumínio com um lábio interior em } \\
\text { silicone. Verificou-se que esta junta } \\
\text { pode ser substituída por uma aplicação } \\
\text { de junta líquida em silicone. }\end{array}$ & $\begin{array}{l}\text { Redução de custo de } 84 \% \text { no } \\
\text { custo da junta e } 0,57 \% \text { no } \\
\text { custo do subsistema } \\
\text { “estrutural e vedações”. }\end{array}$ \\
\hline $\begin{array}{l}\text { Eliminação da pintura } \\
\text { eletrostática. }\end{array}$ & $\begin{array}{l}\text { Com a redução do tempo de transporte } \\
\text { de um mês para dois dias, esse nível de } \\
\text { proteção tornou-se desnecessária. }\end{array}$ & $\begin{array}{l}\text { Redução de custo de } 0,26 \% \\
\text { no custo do Carter de óleo e } \\
0,03 \% \text { no custo do } \\
\text { subsistema “estrutural e } \\
\text { vedações”. }\end{array}$ \\
\hline $\begin{array}{l}\text { Eliminação do o’ring do } \\
\text { tampão de dreno de óleo. }\end{array}$ & $\begin{array}{l}\text { Estes dois componentes podem ser } \\
\text { substituídos por um tampão com rosca } \\
\text { cônica. }\end{array}$ & $\begin{array}{l}\text { Redução de custo de } 40 \% \text { no } \\
\text { custo do tampão e } 0,3 \% \text { no } \\
\text { custo do subsistema. }\end{array}$ \\
\hline
\end{tabular}

Tabela 5 - Modificações sugeridas para a caixa de engrenagem

\begin{tabular}{|l|l|l|}
\hline \multicolumn{2}{|c|}{ Caixa de engrenagem (impacta em 1,55\% dos 37,915\%) } \\
\hline \multicolumn{1}{|c|}{$\begin{array}{c}\text { Modificações } \\
\text { sugeridas }\end{array}$} & \multicolumn{1}{c|}{ Justificativa } & \multicolumn{1}{c|}{ Impactos no custo } \\
\hline $\begin{array}{l}\text { Eliminação da junta da } \\
\text { tampa frontal, que veda a } \\
\text { tampa frontal e a caixa de } \\
\text { engrenagens }\end{array}$ & $\begin{array}{l}\text { Esta junta é composta de uma liga de } \\
\text { alumínio com um lábio interior em } \\
\text { silicone. Esta junta pode ser substituída } \\
\text { por uma aplicação de junta líquida em } \\
\text { silicone. }\end{array}$ & $\begin{array}{l}\text { Redução de custo de 0,79\% } \\
\text { do custo da junta e 0,53\% do } \\
\text { custo do subsistema } \\
\text { "Estrutural e vedações” }\end{array}$ \\
\hline
\end{tabular}

\section{Conclusão}

Este estudo apresentou a aplicação do método DFMA em um motor a diesel, com o objetivo de reduzir custos de fabricação e montagem para que este se tornasse economicamente viável.

Para a aplicação do método DFMA, o estudo mostrou a identificação do subsistema mais crítico em função do impacto de custo no motor e, deste subsistema, os componentes mais representativos.

Identificou-se que o subsistema "Estrutural e vedações" representava 37,915\% no custo total dos componentes relevantes do motor, do ponto de vista do custo.

Dos componentes pertencentes a esse subsistema, quatro componentes foram escolhidos para serem submeti- 
dos ao estudo em função do percentual de custo dentro dos 37,915\%: o bloco de cilindros (19,99\%), o cabeçote (8,35\%), o cárter de óleo (3,67\%) e a caixa de engrenagem (1,55\%). Os outros componentes mostraram percentuais abaixo de $1,5 \%$ dos $37,915 \%$, sendo, portanto, desconsiderados neste estudo.

Como resultado geral, foi obtido apenas $0,71 \%$ de redução de custo no motor estudado, significando 1,14\% no subsistema estudado, o que ainda inviabiliza a fabricação deste produto.

Porém, foram identificadas outras possibilidades de análise e melhoria com o DFMA que poderiam ser realizadas em trabalhos futuros, podendo resultar em um maior impacto na redução do custo total do motor.

Entre as alterações que se mostraram possíveis estão as seguintes: reduzir tolerâncias do bloco fundido, remover as guias e assento de válvulas que são prensadas e substituí-las por usinagem e posterior tratamento térmico e reduzir especificações de acabamentos para superfícies onde podem ser aplicadas juntas de silicone.

Sendo assim, recomenda-se que o analista não se restrinja a focar apenas nos componentes de maior impacto econômico e, sim, se permita explorar as diversas possibilidades no produto como um todo visando uma redução de custo mais significativa.

Com o estudo, no entanto, foi possível perceber a importância do conhecimento técnico dos processos de fabricação e montagem envolvidos, além do conhecimento dos engenheiros de produto/projetistas, sendo necessário, portanto, a aplicação do método em equipe.

\section{Agradecimentos}

Agradecemos a empresa que possibilitou a realização deste estudo e a Professora Fernanda Cervi Rolkouski pelo apoio na tradução da língua portuguesa para a inglesa.

Tabela 6 - Características analisadas, propostas de melhorias e respectivas reduções de custos

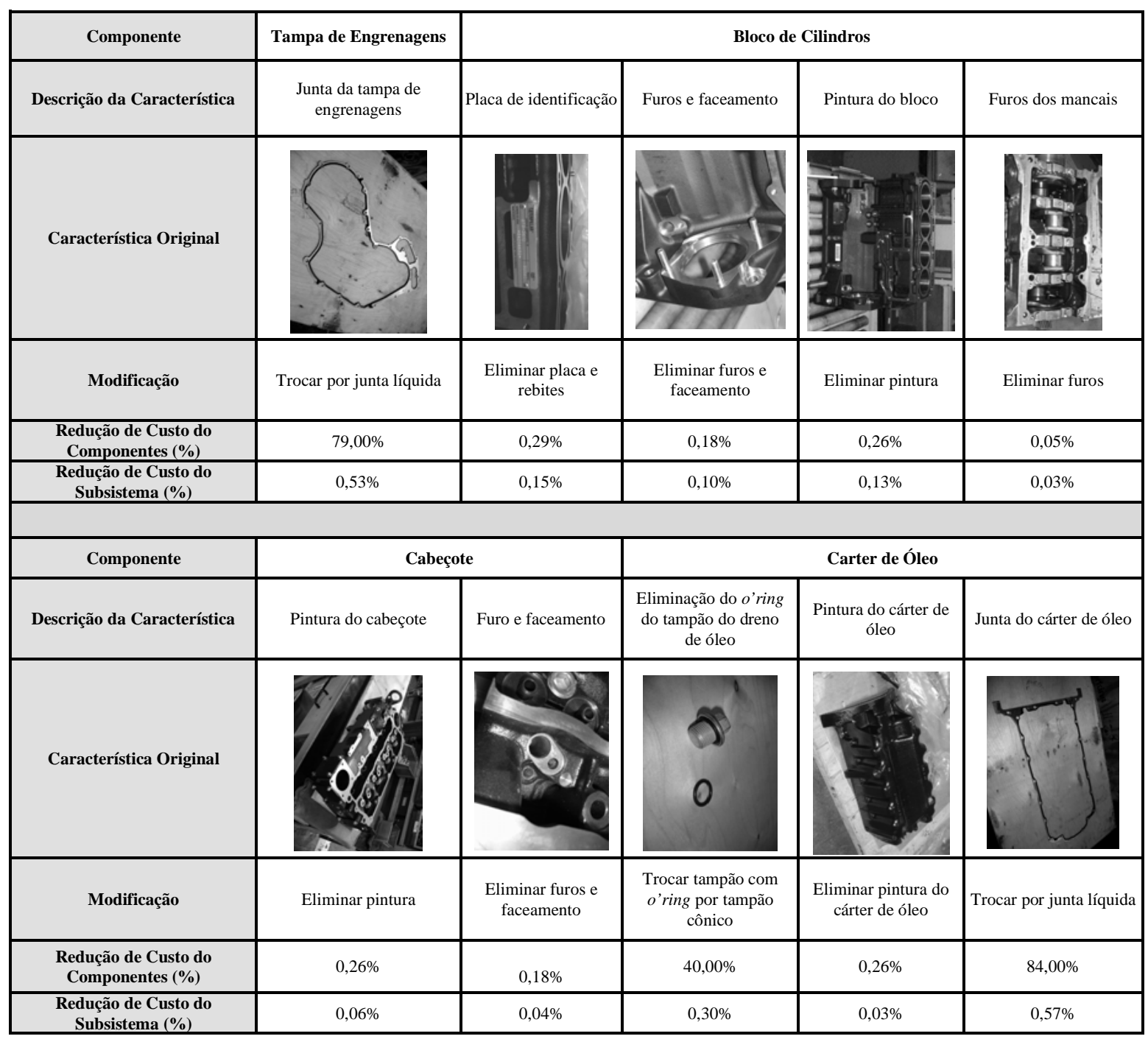




\section{Referências}

AKAO, Y. Introdução al Desdobramento da Qualidade: Manual de Aplicação do Desdobramento de la Função Qualidade. Belo Horizonte: Fundação Cristiano Ottoni , 1990.

ANDREASEN, M. M.; KÄHLER, S.; LUND, T. Design for Assembly. UK: IFS Publications; Berlin, Heidelberg, New York, Tokyo: Springer-Velag, 1988.

BACK, N.; OGLIARI, A. Desenvolvimento do produto: engenharia simultânea. Florianópolis: Programa de PósGraduação en Engenharia Mecânica da UFSC, 2000. (Apostila de gestão de desenvolvimento de produtos).

BARNETT, B. D.; CLARK, K. B. Problem solving in product development: a model for the advanced materials industries. International journal of technology management, v.15, n.8, p. 805-820, 1998.

BLACKBURN, J.D. Time based competition: the next battleground in American manufacturing. Homewood, IL: ed. Business One Irwin, 1991.

BOOTHROYD, G. Product design for manufacture and assembly. New York: Marcel Dekker, 1994.

BOOTHROYD, G.; DEWHURST, P. Product Design for Assembly. Wakefield: Boothroyd Dewhurst, Inc., 1990.

ESTORILIO, Carla. O trabalho dos engenheiros em situações de projeto de produto: uma análise de processo baseada na ergonomia. Tese (Doutorado em Engenharia) Universidade de São Paulo. São Paulo, 2003.

HUANG, G. Q. Design for X. London: Chapman \& Hall, 1996.

JONEJA, A. Design for Manufacturing/Assembly (DFM, DFA, DFMA). Department of Industrial Engineering and Engineering Management (IEEM), Hong Kong University of Science and Technology. Disponível em http:// iesu5.ieem.ust.hk/dfaculty/ajay/courses/ieem317/lecs/ dfm/dfm.pdf. Acesso em: agosto, 2005.

LOCTITE. Fichas Técnicas. Disponível em http:// www.loctite.com.br/int_henkel/loctite_br/ index.cfm?pageid=101\&layout=2 Acesso em: 25 de Jan. de 2006.

PALADY, P. FMEA: análise dos modos de falha y efeitos: prevendo y prevenindo problemas antes que ocorram. São Paulo: IMAM, 2002.
PEREIRA, M. W. \& MANKE, A. L. MDPA - uma metodologia de desenvolvimento de produtos aplicado à engenharia simultânea. In: $3^{\circ}$ Congreso Brasileiro de Gestão de Desenvolvimento de Produto, Florianópolis, Anais. 2001.

PERKINS ENGINES CORP. 1100 Series 1104A-44Engine Specifications, 2004.

RAYNAL, B. Introdução ao estudo e aos ensaios dos motores de combustão. Curso de Especialização em Motores e Combustíveis do Programa Brasileiro de Formação em Motores e Combustíveis - UTFPR, 2005.

ROZENFELD, H.; FORCELLINI, F. A.; AMARAL, D. C.; TOLEDO, J. C.; SILVA, S. L.; ALLIPRANDINI, D. H.; SCALICE, R. K. Gestão de desenvolvimento de produtos: uma referência para a melhoria do processo. São Paulo: Saraiva, 2006.

SAVOIE, M. J. et al. 80/20: quality of design in system development. In: 44thANNUAL QUALITY CONGRESS, San Francisco, 1990. Proceedings...California: Transactions-ASQC, 1990. p. 297-302.

STONE, R. Introduction to internal combustion engines SAE, 1995.

VELASQUEZ, J. A. A. Introdução aos motores de combustão interna. Curso de Especialização em Motores e Combustíveis do Programa Brasileiro de Formação em Motores e Combustíveis - UTFPR, 2005.

WHEELWRIGHT, S.; CLARK, K. Revolutionizing product development. New York: The Free Press, 1992.

YANG, K.; EL-HAIK, B. Design for six sigma: a roadmap for product development. London : McGraw-Hill, 2003. 